\title{
Sensory neuropathy and metabolic risk factors in human immune deficiency virus infected South Africans receiving protease inhibitors
}

\author{
John-Randel Vermaak', Joel A. Dave², Naomi Levitt² and Jeannine M. Heckmann*
}

\begin{abstract}
Background: Protease inhibitors (PI)s have been associated with distal sensory polyneuropathy (DSP) and metabolic complications in high-income countries. No data exist in Africans where second-line antiretroviral therapy (ART) often include Pls.

Method: We performed a cross-sectional study to assess the DSP frequency and metabolic risk factors in community-based South Africans taking ritonavir-boosted lopinavir as PI. Examination findings categorized subjects as having DSP ( $\geq 1$ neuropathic sign) or symptomatic DSP [DSP with symptom(s)]. Fasting-state glucose and lipid profiles were assessed. We compared the ritonavir/lopinavir-group to a nested group on first-line ART [dideoxy-nucleoside reverse transcriptase inhibitors (d-drugs)] selected from a dataset collected at the same time and matched for $d$-drug exposure.

Results: The ritonavir/lopinavir-group $(n=86)$ consisted predominantly of women (84 \%) with a median age of 36 years (IQR 32-41). The median current CD4+ count was 489 cells/ $\mu \mathrm{L}$ (IQR 291-665). The median exposure time to ritonavir/lopinavir was 18 months (IQR 10-26) and to d-drugs, 24 months (IQR 16-38). DSP was present in $78 \%$ and symptomatic DSP in $48 \%$; symptoms were most frequently of moderate intensity. Only age independently associated with DSP and symptomatic DSP ( $p=0.08$ and $p=0.04$, respectively). None of the metabolic syndrome components showed associations with DSP or symptomatic DSP despite a trend towards hypertriglyceridemia overall. The ritonavir/lopinavir-group had less DSP compared to the $d$-drug only group $(p=0.002)$ but the frequency of symptomatic DSP was similar ( $p=0.49$ ).
\end{abstract}

Conclusion: Ritonavir-boosted lopinavir did not add additional risk to developing DSP in this community-based African cohort after a median of 18 months on second-line ART.

Keywords: Lopinavir, Ritonavir, Distal sensory polyneuropathy, Metabolic, Triglycerides, Dysglycemia, Protease inhibitors, African, Symptomatic neuropathy, Anti-retroviral therapy

\section{Background}

Distal sensory polyneuropathy (DSP) is a common neurological complication amongst people living with HIV. Reported frequencies of DSP range between 4 and $83 \%$

\footnotetext{
*Correspondence: jeanine.heckmann@uct.ac.za

${ }^{1}$ Neurology Research Group, Division of Neurology, Department of Medicine, University of Cape Town, Cape Town, South Africa Full list of author information is available at the end of the article
}

depending on the population studied and the DSP definition used [1]. The clinical relevance of DSP is that a proportion of patients frequently complain of neuropathic symptoms such as pain, paresthesia or numbness in the feet which can affect their quality of life, work ability and adherence to therapies [1,2]. Effective treatment is limited. Antiretroviral agents from the dideoxynucleoside reverse transcriptase inhibitor class (d-drugs) which includes stavudine and didanosine, are known to 
associate with the development of symptomatic DSP $[1$, 2].

Previously, in a cross-sectional community-based sample, we reported a high frequency of DSP among South Africans receiving first-line anti-retroviral therapy (ART), which at that time, contained stavudine. In alignment with the World Health Organization recommendations of the time [3], the South African government second-line ART regimen included ritonavir-boosted lopinavir (ritonavir/lopinavir) in combination with two nucleoside reverse transcriptase inhibitors (NRTI), stavudine or didanosine and lamivudine. Reports from North America noted associations between protease inhibitor (PI) exposure (indinavir, saquinavir, ritonavir, amprenavir, lopinavir) and DSP [4-7]. In addition, PI use among individuals from developed countries, usually older males, has been associated with the development of diabetes and hypertriglyceridemia $[8,9]$, which are also associated with DSP $[7,10,11]$. These cohorts differ substantially from the vast majority of people presently receiving PIs in sub-Saharan Africa; for example, African cohorts are young, predominantly women, with very low hepatitis $\mathrm{C}$ co-infectivity and intravenous drug abuse [12]. There are no data on the frequencies of DSP and metabolic risk factors in African cohorts on PIs. Here we assessed the association between DSP and metabolic factors in a community-based South African cohort on second-line ritonavir/lopinavir-based ART. Secondly, we compared the frequencies of DSP to that of a nested-group who had remained on first-line stavudine-containing ART and were matched for a similar duration of ART.

\section{Results}

\section{Study population characteristics}

The ritonavir/lopinavir-group $(\mathrm{n}=86)$ had a median age of 36 years and the majority were women $(84 \%)$. Their median current CD4+ count was 480 cells/ $\mu \mathrm{L}$ although the nadir pre-ART $\mathrm{CD} 4+$ counts were frequently $<100$ cells $/ \mu L$ (Table 1). Overall, these participants had been on the government-sponsored ART program for a median of 36 months and their median exposure to ritonavir/lopinavir was 18 months (IQR 10-28 months). In most cases (55\%) second-line ART was started after virological failure of first-line regimens and in $26 \%$ it was started due to side effects on first-line ART including symptomatic hyperlactataemia (presence of nausea, vomiting, abdominal pain or weight loss and plasma lactate $>2.5 \mathrm{mmol} / \mathrm{L})(\mathrm{n}=5)$, "neuropathy" $(\mathrm{n}=4)$, druginduced hepatitis $(\mathrm{n}=4)$, lipodystrophy $(\mathrm{n}=4)$ and nevirapine-associated rash $(\mathrm{n}=3)$. Pregnancy resulted in a switch to PIs in 7 and in $12 \%$ we were unable to determine the reason for changing from first-line ART. All participants had previous or current d-drug exposure including stavudine (90\%) and/or didanosine (64\%). First-line ART at the time of this study comprised stavudine or zidovudine, lamivudine and nevirapine or efavirenz. Second-line ART comprised stavudine or didanosine (if stavudine was a first-line agent), lamivudine and ritonavir/lopinavir-group. No individuals were taking statins or concomitant oral hypoglycemic agents.

\section{Frequencies and risk factors of distal sensory polyneuropathy}

DSP was present in 67 (78\%) of individuals in the ritonavir/lopinavir-group and symptomatic DSP in 41 (48 \%) (Table 1). Pain and/or paresthesiae were more frequent complaints than numbness (78 vs. $66 \%$ ) and the symptom severity grade was most often classified as moderate (Additional file 1: Table S1). Altered reflexes, either reduced or absent, was the most frequent neuropathic findings in both DSP (73\%) and symptomatic DSP (85\%), altered distal vibration sense in $63-64 \%$ of subjects and impaired distal pain sensibility in $37-39 \%$ of those with DSP and symptomatic DSP, respectively. Mild/moderate weakness of the toes/ankles was present in $\leq 25 \%$.

Those with DSP were older (37 vs. 33 years, $\mathrm{p}=0.007$ ) with lower current CD4+ counts (418 vs. 576 cells/ $\mu \mathrm{l}, \mathrm{p}=0.030)$ although their nadir $\mathrm{CD} 4+$ counts were similar to those without DSP. In addition, subjects with DSP compared to those without DSP had lower macronutritional indicators including bodyweight (64 vs. $95 \mathrm{~kg}$; $\mathrm{p}<0.001)$, body mass index (BMI) $\left(25.1 \mathrm{vs.} 34.5 \mathrm{~kg} / \mathrm{m}^{2}\right.$; $\mathrm{p}=0.005)$ and waist circumference $(85.0$ vs. $103.7 \mathrm{~cm}$; $\mathrm{p}=0.001)$. Obesity $\left(\mathrm{BMI}>30 \mathrm{~kg} / \mathrm{m}^{2}\right)$ was present in $22 \%$ of the DSP group and $54 \%$ of those without DSP $(\mathrm{p}=0.009)$. A multivariate logistic regression model found none of these factors independently associated with DSP although a trend remained with those older than 36 years $(\mathrm{p}=0.08$; Table 2$)$.

Symptomatic DSP also showed significant associations with age $(\mathrm{p}=0.007)$ and lower macro-nutritional indicators including bodyweight $(\mathrm{p}=0.008), \mathrm{BMI}(\mathrm{p}=0.018)$ and waist circumference $(\mathrm{p}=0.017)$, but on multivariate analyses only age remained as an independent risk factor ( $\mathrm{p}=0.042$; Table 2). A history of previous tuberculosis infection(s) showed a trend towards associating with symptomatic DSP $(\mathrm{p}=0.059)$.

\section{Metabolic factors and distal sensory polyneuropathy}

Dysglycemia was found in $41 \%$ of the ritonavir/lopinavir-group although neither the fasting glucose nor OGTT values associated with DSP or symptomatic DSP (Table 1). Hypertriglyceridemia, defined as fasting triglycerides $\geq 1.7 \mathrm{mmol} / \mathrm{L}$ ( $\geq 150 \mathrm{mg} / \mathrm{dl}$ ), was found in $29 \%$, but fasting triglyceride levels did not show an association with neuropathy status (Table 2). Low density lipoprotein 
Table 1 Clinical and laboratory characteristics of DSP and symptomatic DSP in the ritonavir/lopinavir-group ( $n=86)$

\begin{tabular}{|c|c|c|c|c|c|c|}
\hline & Normal value & No DSP $(n=19)$ & $\operatorname{DSP}(n=67)$ & $P$ value & Symptomatic DSP $(n=41)$ & $P$ value \\
\hline Age, years & & $33(27-36)$ & $37(33-43)$ & 0.007 & $37(34-42)$ & 0.007 \\
\hline Female, $n(\%)$ & & $17(89)$ & $55(82)$ & 0.45 & $33(80)$ & 0.39 \\
\hline Alcohol $^{\mathrm{a}}, n(\%)$ & & $8(42)$ & $21(32)$ & 0.41 & $14(34)$ & 0.55 \\
\hline Previous TB, $n(\%)$ & & $12(63)$ & $49(74)$ & 0.35 & $35(85)$ & 0.059 \\
\hline Total d-drug exposure, mo. & & $26(12-36)$ & $24(18-38)$ & 0.67 & $22(15-39)$ & 0.53 \\
\hline Stavudine exposure, mo. & & $15(11-34)$ & $15(10-22)$ & 0.33 & $15(8-25)$ & 0.32 \\
\hline Didanosine exposure, mo. & & $19(12-21)$ & $13(7-23)$ & 0.24 & $13.5(7-25.5)$ & 0.29 \\
\hline LPV/r exposure, mo. & & $21(12-35)$ & $18(10-26)$ & 0.08 & $18(10-26)$ & 0.24 \\
\hline CD4 nadir, cells/ $\mu \mathrm{L}$ & & $84(54-180)$ & $96(37-122)$ & 0.28 & $68(25-120)$ & 0.13 \\
\hline CD4 current, cells/ $\mu \mathrm{L}$ & & $576(467-726)$ & $418(251-610)$ & 0.030 & $472(251-752)$ & 0.15 \\
\hline Viral load at ART initiation & & $184,563(30,438-244,623)$ & $96,645(36,820-241,495)$ & 0.54 & $108,572(36,858-280,000)$ & 0.92 \\
\hline Height (m) & & $1.64(1.63-1.66)$ & $1.61(1.56-1.65)$ & 0.15 & $1.62(1.58-1.68)$ & 0.45 \\
\hline Weight (kg) & & $95(70-98)$ & $64(57-76)$ & $<0.001$ & $68.5(59.9-82)$ & 0.008 \\
\hline Body mass index $\left(\mathrm{kg} / \mathrm{m}^{2}\right)$ & $<25$ & $34.5(26.0-38.5)$ & $25.1(23.3-29.5)$ & 0.005 & $26.1(23.26-30.29)$ & 0.018 \\
\hline Waist circumference $(\mathrm{cm})$ & & $103.7(92.5-109.5)$ & $85.0(78.5-93.5)$ & 0.001 & $87.0(78.5-99)$ & 0.017 \\
\hline $\begin{array}{l}\text { Systolic blood pressure } \\
(\mathrm{mmHg})\end{array}$ & & $110(103-125)$ & $107(102-109)$ & 0.13 & $107(102-119)$ & 0.15 \\
\hline Pre-diabetes, n (\%) & & $5(26)$ & $22(33)$ & 0.59 & $11(27)$ & 0.97 \\
\hline Diabetes, $n(\%)$ & & $2(11)$ & $6(9)$ & 0.84 & $4(10)$ & 0.93 \\
\hline Total cholesterol (mmol/L) & $<5.17$ & $4.58(4.13-5.49)$ & $4.33(3.69-5.35)$ & 0.56 & $3.98(3.66-5.05)$ & 0.20 \\
\hline HDL (mmol/L) & $>1.03$ & $0.93(0.75-1.20)$ & $0.99(0.80-1.17)$ & 0.79 & $0.98(0.76-1.17)$ & 0.99 \\
\hline $\mathrm{LDL}(\mathrm{mmol} / \mathrm{L})$ & $<2.60$ & $3.18(2.66-3.39)$ & $2.56(2.18-3.14)$ & 0.21 & $2.46(2.12-3.00)$ & 0.06 \\
\hline Triglycerides (mmol/L) & $<1.70$ & $1.23(0.97-1.57)$ & $1.36(0.89-1.92)$ & 0.91 & $1.29(0.93-1.79)$ & 0.79 \\
\hline Fasting lactate (mmol/L) & $<1.5$ & $2.3(1.5-2.9)$ & $2.1(1.7-2.8)$ & 0.73 & $2.2(1.7-3.0)$ & 0.81 \\
\hline
\end{tabular}

All continuous variables shown as median value (inter quartile range). Pre-diabetes defined as fasting plasma glucose (FPG) $\geq 5.6 \mathrm{mmol} / \mathrm{L}$ but $<7.0 \mathrm{mmol} / \mathrm{L}$ or 2 - $\mathrm{h}$ plasma glucose during the oral glucose tolerance test $[\mathrm{OGTT}] \geq 7.8 \mathrm{mmol} / \mathrm{L}$ but $<11.1 \mathrm{mmol} / \mathrm{L}$. Diabetes defined as FPG $\geq 7.0 \mathrm{mmol} / \mathrm{L}$ or $2-\mathrm{h}$ OGTT $\geq 11.1 \mathrm{mmol} / \mathrm{L}$ $D S P$ distal sensory polyneuropathy, defined by the presence of $\geq 1$ neuropathic sign, symptomatic DSP DSP in the presence $\geq 1$ neuropathic symptom, Mo. months, $L P V / r$ ritonavir/lopinavir

Italic values indicate statistically significant $P$ values

a Any alcohol use in the past 12 months. P values for DSP and symptomatic DSP derived by comparing with no DSP

(LDL) levels were not associated with DSP but individuals with symptomatic DSP had a trend $(\mathrm{p}=0.06)$ towards lower values.

\section{Protease inhibitors $+d$-drugs vs. $d$-drugs only and the risk} of distal sensory polyneuropathy

As reports from high-income countries previously alluded to an additional risk of PIs and DSP we next compared the frequencies of DSP in this ritonavir/lopinavirgroup who had prior exposure to NRTI-drugs as first-line therapy, and a nested NRTI-group remaining on first-line ART but matched for overall d-drug exposure (Table 3 ). Although the two groups had similar age distributions $(\mathrm{p}=0.57)$ they differed in several aspects; the ritonavir/lopinavir-group had proportionately more women $(\mathrm{p}=0.019)$, lower nadir CD4+ counts $(\mathrm{p}=0.044)$ and higher lactate levels $(p=0.013)$. The ritonavir/lopinavir-group was taller (1.62 vs. $1.51 \mathrm{~m}$; $\mathrm{p}<0.0001)$ with lower BMI values $(\mathrm{p}=0.036)$ but they had larger waist circumference values $(p=0.029)$. The ritonavir/lopinavir-group had higher fasting triglyceride levels (1.29 vs. $1.10 \mathrm{mmol} / \mathrm{L}, \mathrm{p}=0.021)$ and more participants met criteria for hypertriglyceridemia (29 vs. $12 \%, p=0.031$ ). However, the proportion of participants with DSP was lower in the ritonavir/lopinavir-group (78 \%) when compared with the nested d-drug only group (94\%; odds ratio $=0.22$; $95 \%$ CI $0.07-0.6 ; \mathrm{p}=0.002)$ and the frequencies of symptomatic DSP were similar in both groups (48 vs. $53 \%, \mathrm{p}=0.49$ ).

\section{Discussion}

We present the first cross-sectional evaluation of the frequency and risk factors of DSP in a HIV-infected African cohort receiving the protease inhibitor, ritonavir/lopinavir, as second-line ART for approximately 12-24 months. The frequency of DSP (using the non-stringent but standard definition) was high at $78 \%$, but importantly, almost half of the cohort (48\%) had symptomatic DSP. 
Table 2 Multivariate analysis of risk factors for DSP and symptomatic DSP in the ritonavir/lopinavir-group

\begin{tabular}{lllll}
\multicolumn{2}{l}{ Univariate analysis } & & \multicolumn{2}{l}{ Multivariate analysis } \\
\cline { 1 - 2 } $\begin{array}{l}\text { Odds ratio } \\
(95 \% \mathrm{Cl})\end{array}$ & P value & & $\begin{array}{l}\text { Odds ratio } \\
(95 \% \mathrm{Cl})\end{array}$ & P value \\
& & &
\end{tabular}

DSP

\begin{tabular}{|c|c|c|c|c|}
\hline \multicolumn{5}{|c|}{ Age $>36$ years } \\
\hline Yes & $3.9(1.26-12.08)$ & 0.018 & $7.0(0.88-55.65)$ & 0.08 \\
\hline No & 1 & & & \\
\hline \multicolumn{5}{|c|}{$\mathrm{BMI}<30 \mathrm{~kg} / \mathrm{m}^{2}$} \\
\hline Yes & $6.19(1.56-24.47)$ & 0.009 & $0.38(0.03-5.37)$ & 0.47 \\
\hline No & 1 & & & \\
\hline \multicolumn{5}{|c|}{ Waist circumference increased ${ }^{a}$} \\
\hline Yes & $0.18(0.54-0.60)$ & 0.005 & $1.33(0.11-15.5)$ & 0.82 \\
\hline No & 1 & & & \\
\hline \multicolumn{5}{|c|}{ Current CD4 count $<250$ cells $/ \mu \mathrm{L}$} \\
\hline Yes & $5.88(0.73-47.58)$ & 0.09 & $0.43(0.03-6.20)$ & 0.54 \\
\hline No & 1 & & & \\
\hline \multicolumn{5}{|c|}{ Symptomatic DSP } \\
\hline \multicolumn{5}{|c|}{$\begin{array}{l}\text { Age } \\
>36 \text { years }\end{array}$} \\
\hline Yes & $4.38(1.32-14.50)$ & 0.016 & $7.39(1.07-50.77)$ & 0.042 \\
\hline No & 1 & & & \\
\hline \multicolumn{5}{|c|}{$\mathrm{BMl}<30 \mathrm{~kg} / \mathrm{m}^{2}$} \\
\hline Yes & $4.14(1.00-17.05)$ & 0.049 & $0.38(0.03-5.62)$ & 0.38 \\
\hline No & 1 & & & \\
\hline \multicolumn{5}{|c|}{ Waist circumference increased ${ }^{a}$} \\
\hline Yes & $0.23(0.06-0.81)$ & 0.023 & $1.86(0.12-29.60)$ & 0.66 \\
\hline No & 1 & & & \\
\hline
\end{tabular}

$D S P$ distal sensory polyneuropathy, defined by the presence of $\geq 1$ neuropathic sign, symptomatic DSP DSP in the presence $\geq 1$ neuropathic symptom, BMI body mass index

${ }^{a}$ Defined as a waist circumference of $>88 \mathrm{~cm}$ for women and $>102 \mathrm{~cm}$ for men

In contrast, after a similar period of ART, North American cohorts showed DSP frequencies of $\approx 32-50 \%$ and symptomatic DSP of $\approx 20 \%$ [7]. Interestingly, we found that a comparator $\mathrm{d}$-drug only group matched for the duration of d-drug exposure as first-line ART, showed similar frequencies of symptomatic DSP. This suggests that the PI-regimen was not conferring additional risk to developing DSP. An important aim of this study was to investigate the association of DSP and metabolic factors given the potential of ritonavir/lopinavir to induce dysglycemia and dyslipidemia [8]. However, we found no associations between these metabolic factors and DSP or symptomatic DSP.

This African cohort had relatively advanced HIVdisease when starting ART, and after 2-3 years on ART, older age was the only independent risk factor for symptomatic DSP. Advancing age remains the most consistent factor associated with DSP and symptomatic DSP in both
ART-naïve and ART-exposed cohorts irrespective of the ART regimen $[1,2,7,13,14]$. In many HIV-infected cohorts comprising mostly of men, height has been associated with symptomatic DSP $[14,15]$. We have not found this association in either a previous [2], or this current cohort, both of which consisted mostly of indigenous black South African women. Similar to previous reports from Africa, a previous history of tuberculosis was again shown to segregate with symptomatic DSP $[2,16]$. There are multiple reasons why HIV/TB co-infected individuals might be at greater risk of DSP including treatment with isoniazid, micronutrient deficiencies including inadequate pyridoxine supplementation and the cumulative oxidative stress of HIV/TB co-infection [16-19].

The broader applicability of our results in the current era of ART has several constraints; firstly, similar to many HIV-infected cohorts in sub-Saharan Africa and differing from the developed world, few individuals in this cohort are older than 40 years. Our participants are predominantly young women and although HIV-infection is expected to accelerate ageing and impact on the metabolic syndrome it may still be too early for the metabolic manifestations of ART. In contrast to our findings, crosssectional North American studies found elevated random [11] and fasting [10] triglyceride levels to be associated with DSP but these cohorts consisted mostly of older men.

\section{Conclusions}

Despite high frequencies of DSP and symptomatic DSP among South Africans receiving ritonavir-boosted lopinavir (for a median of 18 months) following prior exposure to stavudine-containing ART, our result show that this protease inhibitor, was not associated with additional risk of developing DSP. Although we found no association between DSP and metabolic factors after at least 12 months of exposure to protease inhibitors in this relatively young cohort of mostly black women, longer-term observational studies are required as this population ages.

\section{Methods}

\section{Study population and methods}

The participants for this cross-sectional study were recruited between 2008 and 2010 from two community healthcare centers in Cape Town, South Africa. The South African governmental HIV treatment program at the time, used the PI, ritonavir/lopinavir as part of their second-line ART in combination with two NRTI-class drugs. Eligible subjects had to be on ritonavir/lopinavircontaining second-line ART for $\geq 6$ months. Participants were excluded if they had: a history of diabetes mellitus; active opportunistic infection; severe diarrhea (six 
Table 3 Demographics and clinical features in the ritonavir/lopinavir-group compared to the NRTI-only nested controlgroup

\begin{tabular}{|c|c|c|c|c|}
\hline & Normal value & $\begin{array}{l}\text { Ritonavir/lopinavir } \\
n=86\end{array}$ & $\begin{array}{l}\text { D-drug only } \\
n=85\end{array}$ & $P$ value \\
\hline Age, years & & $35(32-41)$ & $36(30-42)$ & 0.57 \\
\hline Female, $n(\%)$ & & $72(84)$ & $58(68)$ & 0.019 \\
\hline Previous tuberculosis, $n$ (\%) & & $61(72)$ & $58(74)$ & 0.71 \\
\hline Alcohol usage, $n(\%)^{\mathrm{b}}$ & & $29(34)$ & $21(25)$ & 0.18 \\
\hline Period on d-drugs, months ${ }^{c}$ & & $24(16-37.5)$ & $23(18-28)$ & 0.33 \\
\hline DSP, $n(\%)$ & & $67(78)$ & $80(94)$ & 0.004 \\
\hline Symptomatic DSP, n (\%) & & $41(48)$ & $45(53)$ & 0.49 \\
\hline Height (m) & & $1.62(1.57-1.65)$ & $1.51(1.44-1.57)$ & $<0.001$ \\
\hline Weight (kg) & & $67(59-85)$ & $66(58-75)$ & 0.10 \\
\hline Body mass index & $<25$ & $26.0(23.6-30.9)$ & $30.0(24.0-34.0)$ & 0.036 \\
\hline Waist circumference $(\mathrm{cm})^{d}$ & & $87.8(79.3-100.3)$ & $83.8(77.5-92.0)$ & 0.029 \\
\hline Systolic BP (mmHg) & & $108(102-119)$ & $108(100-116)$ & 0.81 \\
\hline CD4 current (cells/ $\mu \mathrm{L}$ ) & & $489(291-665)$ & $406(296-564)$ & 0.49 \\
\hline CD4 nadir (cells/ $\mu \mathrm{L}$ ) & & $96(37-132)$ & $120(55-160)$ & 0.044 \\
\hline Viral load at start of ARV & & $102,268(36,820-241,495)$ & $53,000(12,000-360,000)$ & 0.51 \\
\hline Pre-diabetes, $n$ (\%) & & $27(32)$ & $27(39)$ & 0.24 \\
\hline Diabetes, $n(\%)$ & & $8(9)$ & $3(4)$ & 0.35 \\
\hline Total cholesterol (mmol/L) & $<5.17$ & $4.42(3.75-5.41)$ & $4.31(3.45-4.83)$ & 0.11 \\
\hline $\mathrm{HDL}(\mathrm{mmol} / \mathrm{L})$ & $<1.03$ & $0.96(0.76-1.17)$ & $0.97(0.79-1.18)$ & 0.90 \\
\hline Triglycerides (mmol/L) & $<1.70$ & $1.29(0.93-1.82)$ & $1.10(0.80-1.47)$ & 0.021 \\
\hline Hypertriglyceridemia, N (\%) & $>1.70$ & 25(29) & $10(12)$ & 0.031 \\
\hline Fasting lactate (mmol/L) & $<1.5$ & $2.2(1.7-2.9)$ & $1.8(1.4-2.4)$ & 0.013 \\
\hline Hyperlactatemia, $N(\%)$ & $>2.5$ & $32(39)$ & $20(25)$ & 0.06 \\
\hline
\end{tabular}

The results of all continuous variables are shown as median (inter quartile range). DSP distal sensory polyneuropathy as defined by $\geq 1$ neuropathic sign. Symptomatic DSP is defined as $\geq 1$ neuropathic sign and symptom. Prediabetes defined as fasting plasma glucose (FPG) $\geq 5.6 \mathrm{mmol} / \mathrm{L}$ but $<7.0 \mathrm{mmol} / \mathrm{L}$ or 2 - $\mathrm{h}$ plasma glucose during the oral glucose tolerance test (OGTT) $\geq 7.8 \mathrm{mmol} / \mathrm{L}$ but $<11.1 \mathrm{mmol} / \mathrm{L}$. Diabetes defined as FPG $\geq 7.0 \mathrm{mmol} / \mathrm{L}$ or $2-\mathrm{h}$ plasma glucose during the OGTT $\geq 11.1 \mathrm{mmol} / \mathrm{L}$

a The nested controls were extracted from a cohort [2] as outlined in Methods

b Any alcohol use in the prior 12 months

c Defined as the sum of stavudine and didanosine exposure times

d Men $<90 \mathrm{~cm}$, women $<84 \mathrm{~cm}$. P value reflects the comparison of those exposed to ritonavir/lopinavir vs. the matched controls who did not have ritonavir/lopinavir exposure

stools/day); tuberculosis $<1$ month of commencing treatment; received glucocorticoid therapy within the past 6 months; pregnant; known with renal failure; neurological disorder confounding the assessment of neuropathy. The study was approved by the University of Cape Town Research Ethics Committee.

After signing informed consent, study participants were assessed by one of two trained doctors using the Brief Peripheral Neuropathy Screen (BPNS) and a revision of the modified Total Neuropathy Score (TNSr) as previously described $[2,20]$. Supervision of examination procedures by a neurologist was frequent and ongoing throughout the study period. The definition for DSP included the symmetrical distal onset of $\geq 1$ neuropathic sign in the feet: reduced/absent reflexes, impaired distal vibration or pin sensibility. Symptomatic DSP referred to DSP with symmetrical neuropathic symptoms: burning pain, paresthesiae or numbness. Symptom severity was assessed using a visual numerical scale ranging between 0 and 10 and then graded as mild (1-3), moderate (4-6), severe (7-8) and very severe (9-10). Blood pressure and anthropometry (weight, BMI, waist circumference), as well as an oral glucose tolerance test (OGTT) and fasting lipid levels were performed as previously described [21]. Pre-diabetes was defined as fasting plasma glucose (FPG) $\geq 5.6 \mathrm{mmol} / \mathrm{L}$ but $<7.0 \mathrm{mmol} / \mathrm{L}$ or 2 -h OGTT plasma glucose $\geq 7.8 \mathrm{mmol} / \mathrm{L}$ but $<11.1 \mathrm{mmol} / \mathrm{L}$. Diabetes was defined as FPG $\geq 7.0 \mathrm{mmol} / \mathrm{L}$ or 2 -h OGTT $\geq 11.1 \mathrm{mmol} / \mathrm{L}$. Demographic information including drug history was obtained by questionnaire and folder review. 
For comparison, a nested-group on first-line ART (containing the d-drug, stavudine) were selected from a previously described cross-sectional cohort [2] who were recruited from the same clinics, according to the same inclusion/exclusion criteria and underwent evaluations according to the same protocol by the same study team. Although there was some overlap in the study period, this second-line ART study started at least 12 months after the first-line study. The groups were matched for duration of ART and d-drug exposure in the following manner: all subjects on first-line ART $(\mathrm{n}=216)$ and shorter total d-drug exposure times were systematically censored until there was no statistical difference in the exposure times between the nested d-drug cohort and the ritonavir/lopinavir-group. This point was reached when d-drug exposure $\geq 14$ months and included 85 subjects.

\section{Statistical analysis}

For univariate analyses continuous variables were assessed by Shapiro-Wilk testing and non-parametric data was transformed by the most appropriate transformation selected from a ladder of powers of transformations. Student $t$ tests were used for parametric continuous data, Wilcoxon rank-sum tests for nontransformable non-parametric data and Chi square tests for categorical data. Statistical significance was set at the 0.05 level (two-sided). Certain continuous variables were categorized based on clinically relevant cutoff values. Variables showing significant associations were systematically included in a step- wise multivariate logistic regression model. Spearman correlates were used to investigate the relationship between the variables included in each model. All data analyses were performed using STATA/ IC 11.

\section{Additional file}

Additional file 1: Table S1. The neuropathy characteristics of DSP and symptomatic DSP in the ritonavir/lopinavir-group.

\section{Abbreviations \\ ART: antiretroviral therapy; PI: protease inhibitors; DSP: distal sensory poly- neuropathy; IQR: interquartile range; OGTT: oral glucose tolerance test; FPG: fasting plasma glucose; BMI: body mass index.}

\section{Authors' contributions}

$J M H$ and J-RV wrote the first draft of the manuscript. J-RV performed the statistical analyses under supervision. JAD and NSL participated in the design and coordination of the study, and reviewing the manuscript. JMH conceived the idea of the study and participated in its design. All authors read and approved the final manuscript.

\section{Author details}

${ }^{1}$ Neurology Research Group, Division of Neurology, Department of Medicine, University of Cape Town, Cape Town, South Africa. ${ }^{2}$ Division of Endocrinology and Diabetic Medicine, Department of Medicine, University of Cape Town, Cape Town, South Africa.

\section{Acknowledgements}

Thanks to Dr. Henri Cararra from the Department of Public Health and Family Medicine, University of Cape Town, South Africa for the statistical supervision and Drs. Jean Maritz and Johan van der Watt as well as the study coordinator, Carmen Delport who were involved in data collection.

\section{Compliance with ethical guidelines}

\section{Competing interests}

The authors declare that they have no competing interests.

Received: 22 June 2015 Accepted: 10 September 2015

Published online: 23 September 2015

\section{References}

1. Centner CM, Bateman KJ, Heckmann JM. Manifestations of HIV infection in the peripheral nervous system. Lancet Neurol. 2013;12:295-309.

2. Maritz J, Benatar M, Dave JA, Harrison TB, Badri M, Levitt SN, Heckmann JM. HIV neuropathy in South Africans: frequency, characteristics, and risk factors. Muscle Nerve. 2010;41:599-606.

3. World Health Organization. Antiretroviral therapy for HIV infection in adults and adolescents: recommendations for a public health approach-2010 review. http://www.who.int/hiv/pub/arv/adult2010/en/ index.html. Accessed 11 June 2015.

4. Lichtenstein KA, Armon C, Baron A, Moorman AC, Wood KC, Holmberg SD. Modification of the incidence of drug-associated symmetrical peripheral neuropathy by host and disease factors in the HIV outpatient study cohort. Clin Infect Dis. 2005:40:148-57.

5. Pettersen JA, Jones G, Worthington C, Krentz HB, Keppler OT, Hoke A, et al. Sensory neuropathy in human immunodeficiency virus/acquired immunodeficiency syndrome patients: protease inhibitor mediated neurotoxicity. Ann Neurol. 2006;59:816-24.

6. Ellis RJ, Marquie-Beck J, Delaney P, Alexander T, Clifford DB, MCArthur JC, et al. Human immunodeficiency virus protease inhibitors and risk for peripheral neuropathy. Ann Neurol. 2008;64:566-72.

7. Evans SR, Ellis RJ, Chen H, Yeh TM, Lee AJ, Schiffito G, et al. Peripheral neuropathy in HIV: prevalence and risk factors. AIDS. 2011;25:919-28.

8. Carr A, Samaras K, Burton S, Law M, Freund J, Chisholm DJ, Cooper DA. A syndrome of peripheral lipodystrophy, hyperlipidaemia and insulin resistance in patients receiving HIV protease inhibitors. AIDS 1998;12:F51-8.

9. Feeney ER, Mallon PW. HIV and HAART-associated dyslipidemia. Open Cardiovasc Med J. 2011;5:49.

10. Ances BM, Vaida F, Rosario D, Alexander T, Marquie-Beck J, Ellis RJ, et al. Role of metabolic syndrome components in HIV associated sensory neuropathy. AIDS. 2009;23:2317-22.

11. Banerjee S, McCutchan JA, Ances BM, Deutsch R, Riggs PK, Way L, Ellis RJ. Hypertriglyceridemia in combination antiretroviral-treated HIV-positive individuals: potential impact on HIV sensory polyneuropathy. AIDS. 2011;25:F1-6.

12. UNAIDS. Global report: UNAIDS report on the global AIDS epidemic 2012. http://www.unaids.org/en/resources/documents/2012/20121120_ UNAIDS_Global_Report_2012. Accessed 11 June 2015.

13. Robinson-Papp J, Tan IL, Simpson DM. Neuromuscular complications in HIV: effects of aging. J Neurovirol. 2012;18:331-8.

14. Cherry CL, Affandi JS, Imran D, Yunihastuti E, Smyth K, Vanar S, Price P. Age and height predict neuropathy risk in patients with HIV prescribed stavudine. Neurology. 2009;73:315-20.

15. Chen H, Clifford DB, Deng L, Wu K, Lee AJ, Bosch R, Evans SR. Peripheral neuropathy in ART-experienced patients: prevalence and risk factors. J Neurovirol. 2013;19:557-64.

16. Van der Watt JJ, Benatar MG, Harrison TB, Carrara H, Heckmann JM. Isoniazid exposure and pyridoxine levels in HIV-associated distal sensory neuropathy. Int J Tuberc Lung Dis. 2015. http://dx.doi.org/10.5588/ ijtld.15.0467

17. Centner CM, Carrara H, Harrison TB, Benatar M, Heckmann JM. Sensory polyneuropathy in human immunodeficiency virus-infected patients receiving tuberculosis treatment. Int J Tuberc Lung Dis. 2014;18:27-33. 
18. Van der Watt JJ, Harrison TB, Benatar M, Heckmann JM. Polyneuropathy, anti-tuberculosis treatment and the role of pyridoxine in the HIV/AIDS era: a systematic review. Int J Tuberc Lung Dis. 2011;15:722-8.

19. Lehmann HC, Chen W, Borzan J, Mankowski JL, Hoke A. Mitochondrial dysfunction in distal axons contributes to human immunodeficiency virus sensory neuropathy. Ann Neurol. 2011;69:100-10.
20. Cherry CL, Wesselingh SL, Lal L, McArthur JC. Evaluation of a clinical screening tool for HIV-associated sensory neuropathies. Neurology. 2005;65:1778-81.

21. Dave JA, Lambert EV, Badri M, West S, Maartens G, Levitt NS. Effect of nonnucleoside reverse transcriptase inhibitor-based antiretroviral therapy on dysglycemia and insulin sensitivity in South African HIV-infected patients. JAIDS. 2011;57:284-9.

Submit your next manuscript to BioMed Central and take full advantage of:

- Convenient online submission

- Thorough peer review

- No space constraints or color figure charges

- Immediate publication on acceptance

- Inclusion in PubMed, CAS, Scopus and Google Scholar

- Research which is freely available for redistribution

Submit your manuscript at www.biomedcentral.com/submit 